\title{
Angiotensin-converting enzyme 2 regulates endoplasmic reticulum stress and mitochondrial function to preserve skeletal muscle lipid metabolism
}

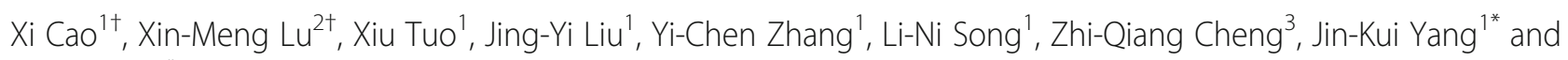
Zhong $\operatorname{Xin}^{1 *}$ (D)

\begin{abstract}
Objective: Endoplasmic reticulum (ER) stress and mitochondrial function affected intramuscular fat accumulation. However, there is no clear evident on the effect of the regulation of ER stress and mitochondrial function by Angiotensin-converting enzyme 2 (ACE2) on the prevention of intramuscular fat metabolism. We investigated the effects of ACE2 on ER stress and mitochondrial function in skeletal muscle lipid metabolism.

Methods: The triglyceride (TG) content in skeletal muscle of ACE2 knockout mice and Ad-ACE2-treated db/db mice were detected by assay kits. Meanwhile, the expression of lipogenic genes (ACCa, SREBP-1c, LXRa, CPT-1a, PGC-1a and PPARa), ER stress and mitochondrial function related genes (GRP78, elF2a, ATF4, BCL-2, and SDH6) were analyzed by RT-PCR. Lipid metabolism, ER stress and mitochondrial function related genes were analyzed by RT-PCR in ACE2overexpression C2C12 cell. Moreover, the IKKB/NFkB/IRS-1 pathway was determined using lysate sample from skeletal muscle of ACE2 knockout mice.

Results: ACE2 deficiency in vivo is associated with increased lipid accumulation in skeletal muscle. The ACE2 knockout mice displayed an elevated level of ER stress and mitochondrial dysfunctions in skeletal muscle. In contrast, activation of ACE2 can ameliorate ER stress and mitochondrial function, which slightly accompanied by reduced TG content and down-regulated the expression of skeletal muscle lipogenic proteins in the db/db mice. Additionally, ACE2 improved skeletal muscle lipid metabolism and ER stress genes in the C2C12 cells. Mechanistically, endogenous ACE2 improved lipid metabolism through the IKKB/NFKB/IRS-1 pathway in skeletal muscle.
\end{abstract}

Conclusions: ACE2 was first reported to play a notable role on intramuscular fat regulation by improving endoplasmic reticulum and mitochondrial function. This study may provide a strategy for treating insulin resistance in skeletal muscle.

Keywords: ACE2, Intramuscular fat, Endoplasmic reticulum, Mitochondrial function

\section{Introduction}

Intramuscular fat is an indispensable energy source for skeletal muscle. These lipids play pivotal roles in metabolism not only for skeletal muscle but also for the entire body. The status of the endoplasmic reticulum (ER) is a significant determinant of protein homeostasis in muscle

\footnotetext{
*Correspondence: jinkui.yang@gmail.com; xinz@medmail.com.cn

${ }^{+} X_{i}$ Cao and Xin-Meng Lu contributed equally to this work.

${ }^{1}$ Beijing Key Laboratory of Diabetes Research and Care, Beijing Diabetes institute, Department of Endocrinology, Beijing Tongren Hospital, Capital Medical University, Beijing 100730, China

Full list of author information is available at the end of the article
}

cells. Accumulation of unfolded proteins and other physiological stresses produces ER stress, which initiates the unfolded protein response (UPR). More importantly, the signaling pathway activated by the ER stress has emerged as a critical regulator of lipid biosynthesis, insulin resistance, inflammation, and apoptosis $[1,2]$.

Excess lipid accumulation and impairment in mitochondrial function have been considered as putative mechanisms for the pathogenesis of skeletal muscle insulin resistance. Mitochondria modulate the balance between lipid metabolism and storage in the skeletal

(c) The Author(s). 2019 Open Access This article is distributed under the terms of the Creative Commons Attribution 4.0 International License (http://creativecommons.org/licenses/by/4.0/), which permits unrestricted use, distribution, and 
muscle. $\beta$-oxidation of fatty acids (FAs) is linked to ATP production, mitochondrial respiration [3], and redox balance [4]. Muscle mitochondria regulate the transport and $\beta$-oxidation flux of long-chain fatty acids [5]. Mitochondrial deficiency as the cause of impaired fatty acid oxidation capacity and skeletal muscle fat accumulation, ultimately leading to the mitochondrial-driven 'lipotoxicity' hypothesis of insulin resistance [6].

Renin-angiotensin system (RAS) plays an important role in the pathogenesis of IR $[7,8]$. Angiotensin-converting enzyme 2 (ACE2) decreases the generation of Ang II by catalyzing the conversion of Ang II to angiotensin-(1-7) (Ang-(1-7)). Ang-(1-7) elicits the opposite effect of Ang II [9]. Recently, we reported that ACE2 regulates mitochondrial function in pancreatic $\beta$-cells, and ACE2 inhibits endoplasmic reticulum stress-associated pathway to preserve hepatic insulin resistance and hepatic steatosis $[10,11]$. Moreover, the beneficial protection against ER stress in heart and lung by ACE2 is reported [12, 13]. However, there is no direct evidence that ACE2 regulates ERS and mitochondrial function in the skeletal muscle.

Though ACE2 influences the lipid metabolism of adipose tissue and liver, its effect on intramuscular fat has never been reported. A previous study reported that Ang(1-7) improved the sensitivity of insulin by skeletal muscle glucose uptake increasement in vivo [14]. However, the underlying mechanism is still unclear. In the present study, we investigated the role of ACE2 in regulating intramuscular fat and its possible behavior on endoplasmic reticulum and mitochondrial function to clarify the function of ACE2 in metabolism and provided a potential target for insulin resistance prevention in skeletal muscle.

\section{Materials and methods}

\section{Animal}

$A C E 2 \mathrm{KO}$ mice were a gift from Prof. Josef Penninger from the Institute of Molecular Biotechnology, Austria. In all experiments, the $A C E 2 \mathrm{KO}$ mice were identified by PCR genotyping assays from tail biopsies. Only male $A C E 2 \mathrm{KO}$ mice (ACE2 ${ }^{-/ y}$ mice) and their age- and sexmatched wild-type (WT) littermates were performed. The male $\mathrm{db} / \mathrm{db}$ mice at the age of 6 weeks were purchased from Nanjing Biological Medicine Research Institute, Nanjing University, China. The $\mathrm{db} / \mathrm{db}$ mice were maintained on the BKS background. All mice were maintained on a $12 \mathrm{~h}$ light/dark cycle. All animals were handled in accordance with the protocol approved by the Ethics Committee of Animal Research at Beijing Tongren Hospital, Capital Medical University, Beijing, China.

\section{Biochemical assays}

Intramyocellular triglycerides were extracted and determined using a triglyceride assay kit (ThermoFisher Scientific) and normalized to tissue weights.

\section{Histochemistry}

Basic muscle morphology was assessed with haematoxylin and eosin staining, according to a standard protocol. All stained, sectioned images were captured under a microscope with a minimum of four fields of view per muscle section at $\times 100$ magnification.

\section{Cell culture}

Undifferentiated mouse $\mathrm{C} 2 \mathrm{C} 12$ myoblasts were maintained in growth medium (GM) (DMEM, Gibco, 11,965092, supplemented with $10 \%$ fetal bovine serum, heat inactivated, $1 \%$ penicillin/streptomycin, $1 \%$ L-glutamine and $1-\mathrm{mM}$ sodium pyruvate). To prepare for differentiation, the cells were seeded at a density of $1.6 \times 10^{5}$ cells/ well in GM in 6-well plates. Differentiation was initiated 2 days later when the cells became confluent by replacing GM with differentiation medium (DM) containing 2\% horse serum in place of $10 \%$ FBS. The medium was changed every other day until transfection, which was performed on day 4-5 after initiation of differentiation. The cells were maintained at $37^{\circ} \mathrm{C}$ with humidified air at $5 \%$ $\mathrm{CO}_{2}$ and passaged by trypsinization.

\section{Overexpression of ACE2 in C2C12 cells and mouse liver}

To overexpress $A C E 2$ in the $\mathrm{db} / \mathrm{db}$ mice, an adenovirus coding for rat $A C E 2$ (rACE2) upstream of an enhanced green fluorescent protein (eGFP) reporter gene (AdrACE2-eGFP) and the control eGFP virus (Ad-eGFP) was respectively injected into the $\mathrm{db} / \mathrm{db}$ mice (male, 5 to 7 -week-old) by tail vein $\left(5 \times 10^{8}\right.$ particle forming units (pfu) in $100 \mu \mathrm{L}$ saline). On the 6th day post-virus injection, glucose tolerance tests (GTT) were performed. On the 7th day, the animals were sacrificed for experimental analysis. The $\mathrm{C} 2 \mathrm{C} 12$ cells were infected with $1.0 \times 10^{7}$ pfu Ad-ACE2 or Ad-GFP for $24 \mathrm{~h}$ to overexpress the ACE2 protein.

\section{Western blot}

Total protein was extracted from muscle tissue and C2C12 cells with RadioImmunoprecipitation Assay (RIPA) lysis buffer, and assessed by the BCA protein assay kit for the amount (Beyotime, China). 30-60 $\mu \mathrm{g}$ protein samples were separated by $10 \%$ SDS-PAGE and transferred to PVDF membranes (Millipore, Billerica, MA, USA). The membranes were blocked with $5 \%$ nonfat dry milk and incubated with antibodies (Abs) at $4{ }^{\circ} \mathrm{C}$ overnight. The blots were probed with HRP-conjugated anti-IgG followed by detection with enhanced chemiluminescence (ECL, Millipore). C/EBP homologous protein (CHOP) $\mathrm{Ab}$, activating transcription factor-4 (ATF4) $\mathrm{Ab}$, Bcl-2 Ab, Bax Ab, NDUFB8 Ab, NFkB Ab, phospho-NFkB $A b$, IKK $\beta$ Ab, phospho-IKK $\beta$ Ab, IRS-1 Ab, phospho-IRS-1 $\left(\mathrm{Ser}^{307}\right) \mathrm{Ab}$, and tubulin $\mathrm{Ab}$ were purchased from Cell Signaling technology. Glucose regulated protein 78 (GRP78) 
$\mathrm{Ab}$ and eIF2a Ab were obtained from Abcam. acetyl-CoA carboxylase $\alpha(\mathrm{ACC} \alpha) \mathrm{Ab}$, liver X receptor- $\alpha(\mathrm{LXR} \alpha) \mathrm{Ab}$, sterol regulatory element-binding protein-1c (SREBP-1c) $\mathrm{Ab}$, and (carnitine palmitoyltransferase $1 \alpha$ ) CPT- $1 \alpha \mathrm{Ab}$ were purchased from Santa Cruz. The $68 \mathrm{kDa}$ band of SREBP-1c was used to calculate the gray value.

\section{Total RNA extraction and real-time PCR}

Total RNA was extracted by Trizol Reagent (Invitrogen). A total of $500 \mathrm{ng}$ of RNA was applied as the template for the first-strand cDNA synthesis by ReverTraAceqPCR RT Kit (TOYOBO, Osaka, Japan). The transcripts were quantified using Light Cycler 480 Real-Time PCR system (Roche, Basel, Switzerland). Primers were designed by Primer Quest (Integrated DNA Technologies, Inc).

\section{Statistical analysis}

All data were presented as the mean \pm SD and analyzed by Student's t-test or one-way ANOVA (with Bonferroni post-hoc tests to compare replicate means) when appropriate. Statistical comparisons were performed by Prism 5 (GraphPad Software, San Diego, CA). $P$ value less than 0.05 were identified to be statistically significant. Representative results from at least three independent experiments were shown unless otherwise stated.

\section{Results}

ACE2 deficiency in vivo displayed lipid accumulation, ER stress and mitochondrial dysfunction in skeletal muscle ACE2 knockout mice $\left(A C E 2^{-/ y}\right)$ were used to evaluate its role in skeletal muscle in vivo. The ACE2 mRNA levels were indeed reduced in the skeletal muscle of the $A C E 2^{-/ y}$ mice (Fig. 1a). Pathological changes were observed in $\mathrm{H} \& \mathrm{E}$ stained $A C E 2^{-/ \mathrm{y}}$ mice skeletal muscle sections. The $A C E 2^{-/ y}$ mice exhibited breakage of fibers and disorder of morphology (Fig. 1b).

The skeletal muscle TG content was significantly higher in $A C E 2^{-/ y}$ mice than the WT mice (Fig. 1c). To further explore these findings, we investigated the expression levels of proteins involved in lipid metabolism using real-time PCR and Western blot. Consistently, the mRNA levels of fatty acid oxidation-related genes, including PPARY coactivator $1 \alpha(P G C-1 \alpha)$, peroxisome proliferator-activated receptor alpha (PPAR $)$, and medium chain acy -CoA dehydrogenase $(M C A D)$ were down-regulated, and little change was observed in PPAR gamma (PPAR $)$ and CPT-1 $\alpha$ in the skeletal muscle of the $A C E 2^{-/ y}$ mice (Fig. 1d). Coinstantaneous, the protein levels of lipid-metabolizing genes, including ACC $\alpha$ and SREBP-1c were up-regulated, whereas the expression of LXR $\alpha$ and CPT- $1 \alpha$ did not exhibit an obvious difference between the $A C E 2^{-/ y}$ and the WT groups (Fig. 1e). These results suggested that deletion of ACE2 may aggravate intramuscular fat accumulate in the $A C E 2^{-/ y}$ mice.
Next, we examined the ER stress in the skeletal muscle. During the ER stress, several specific proteins were highly expressed, including GRP78, pancreatic endoplasmic reticulum kinase-eukaryotic translation initiation factor $2 \alpha(\mathrm{eIF} 2 \alpha)$, binding immunoglobulin protein (BiP), also known as inositolrequiring enzyme $1 \alpha$ (IRE $1 \alpha$ )-Xbox-binding protein-1 (XBP-1), activating transcription factor 4 (ATF4), and CHOP. In this study, the mRNA levels of GRP78, ATF4 and XBP-1 were increased in the $A C E 2$ knockout mice (Fig. 1f). Consistently, the protein levels of GRP78, eIF2 $\alpha$, ATF4, and CHOP were all significantly up-regulated in the skeletal muscle of the $A C E 2^{-/ y}$ mice (Fig. 1g). These results suggested a progressive accumulation of unresolved ER stress in the skeletal muscle of the $A C E 2^{-/ y}$ mice.

To study whether the mitochondrial function affect the skeletal muscle lipid metabolism, the gene levels of mitochondrial complexes I- III were measured. As expected, the mRNA levels of NDUFB8 (Complex I), succinate dehydrogenase subunit B $(S D H B)$ (Complex II), and ubiquinol-cytochrome c reductase complex core protein 2 (UQCRC2) (Complex III) were down-regulated significantly (Fig. 1h), whereas no observable difference was detected in mitochondrial encoded NADH dehydrogenase 1 (mt-ND1) group. These results indicated that the endogenous $A C E 2$ may regulate the expressions of proteins related to ER stress, mitochondrial function and cell apoptotic in mice skeletal muscle.

\section{ACE2 improves skeletal muscle lipid metabolism in vitro and in vivo}

ACE2 was overexpressed in the $\mathrm{C} 2 \mathrm{C} 12$ cells to evaluate its role in lipid metabolism and ER stress by RT-PCR analysis in vitro. Firstly, ACE2 has been proved to be indeed overexpressed after the adenoviruses infect (Fig. 2a). Secondly, the mRNA levels of fatty acid oxidation-related genes, PPAR $\alpha$, PPAR $\gamma$, and $C P T-1 \alpha$ were increased, and little change was observed in $P G C-1 \alpha$ and $M C A D$ in ACE2-overexpressing $\mathrm{C} 2 \mathrm{C} 12$ cells (Fig. 2b). The results showed that the overexpression of ACE2 significantly improved fatty acid oxidation and ER stress.

ACE2 was overexpressed by adenovirus in the $\mathrm{db} / \mathrm{db}$ mice to evaluate its role in skeletal muscle lipid metabolism in vivo. After injection of adenoviruses, RT-PCR result indicated the protein level of ACE2 was overexpressed (Fig. 2c). The content of TG in skeletal muscle of the AdACE2-treated mice was slightly lower than that of AdGFP-treated mice (Fig. 2d). The mRNA levels of fatty acid oxidation-related genes, PGC-1 $\alpha, P P A R \alpha, P P A R \gamma, C P T-1 \alpha$, and $M C A D$ were up-regulated in the skeletal muscle of the Ad-ACE2-treated mice compared to the Ad-GFPtreated mice (Fig. 2e). Moreover, the Ad-ACE2-treated mice exhibited a significant reduction of protein level of SREBP-1c and ACC $\alpha$ in the skeletal muscle (Fig. 2f). 


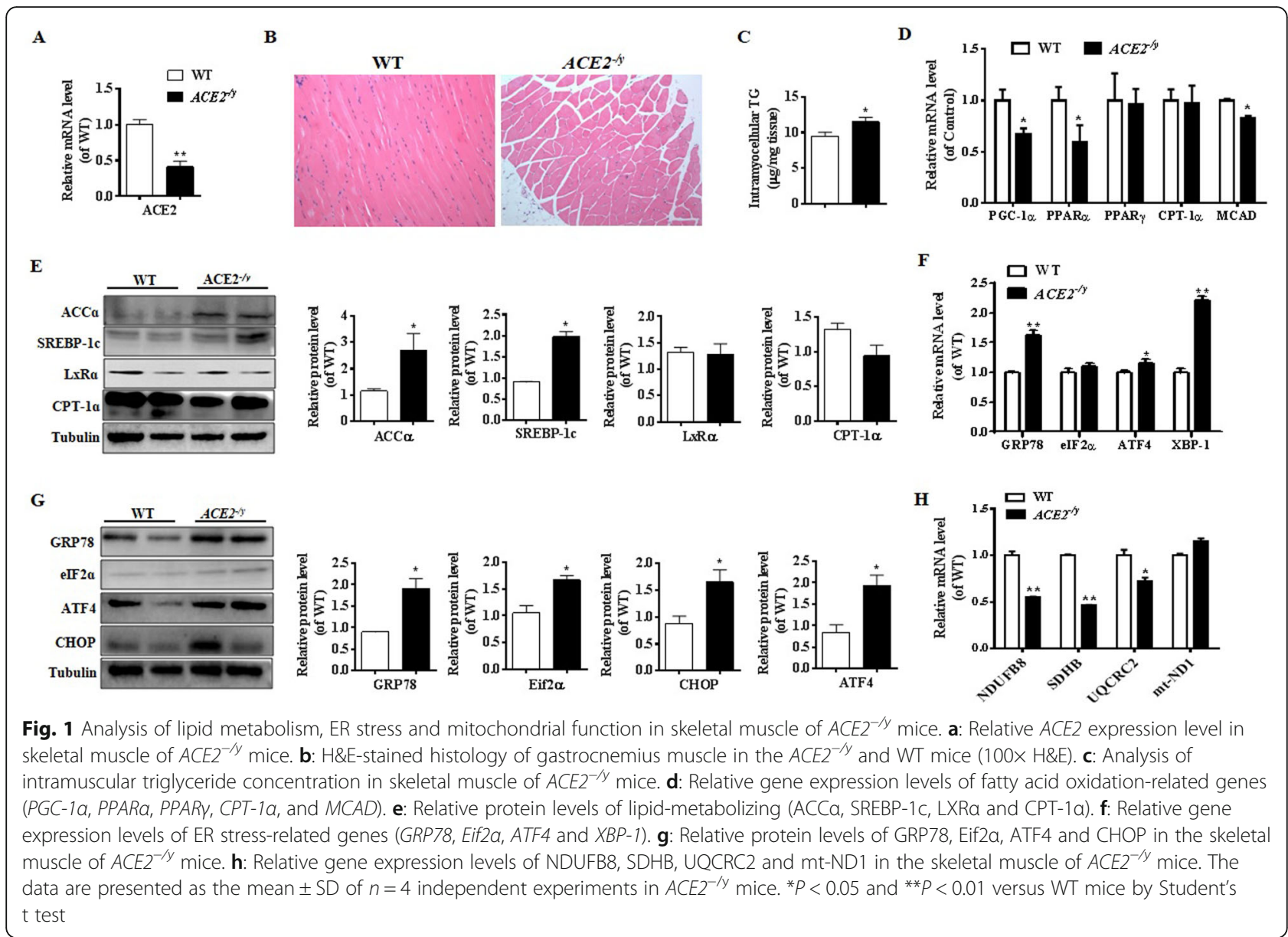

\section{ACE2 ameliorates ER stress and mitochondrial function} in vitro and in vivo

In the $\mathrm{C} 2 \mathrm{C} 12$ cell, the mRNA levels of GRP78, ATF4 and $X B P-1$ were significantly decreased in the ACE2overexpressing cells, but not eIF $2 \alpha$ (Fig. 3a). Inflammation gene $I L-6$ was also reduced in the ACE2-overexpressing C2C12 cells (Fig. 3b).

Meanwhile, pathological changes were observed in the H\&E stained skeletal muscle sections. The Ad-ACE2treated mice demonstrated less structural damage and consistent protection morphology compared to the AdGFP-treated mice (Fig. 3c). Next, we studied whether ACE2 altered the expression of ER stress and mitochondrial function-related genes. We found the mRNA levels of GRP78, ATF4, XBP-1 was depressed (Fig. 3d) and the protein levels of eIF $2 \alpha$ and CHOP were inhibited in the Ad-GFP-treated $\mathrm{db} / \mathrm{db}$ mice (Fig. 3e). Moreover, the mRNA levels of NDUFB8, UQCRC2, and mt-ND1 were increased in the skeletal muscle of the Ad-ACE2-treated mice (Fig. 3f). Additionally, the protein levels of NDUFB8 and Bcl-2 were reduced obviously in the Ad-GFP-treated mice (Fig. 3g). These data indicated ACE2 may significantly improve the skeletal muscle lipid metabolism in the $\mathrm{db} / \mathrm{db}$ mice. These studies also suggested that ACE2 may regulate ER stress and mitochondrial function in the skeletal muscle.

\section{ACE2 regulates the IKK $\beta / N F K B / I R S-1$ pathway in muscle}

To explore a possible mechanism involvement of ACE2 in its beneficial effect against ER stress, we evaluated the expression of the $\mathrm{IKK} \beta / \mathrm{NF} \mathrm{B}$ pathway in the $A C E 2^{-/ \mathrm{y}}$ mice and found the levels of phosphorylated $N_{K} B$ and IKK $\beta$ markedly increased. Although the total amount of NFKB and IKK $\beta$ protein did not change (Fig. 4a). Consistently, IRS-1, which is another important marker of ER stress downstream of $\mathrm{NFKB}$, was also significantly up-regulated in the $A C E 2^{-/ y}$ mice (Fig. 4a). These results suggested that ACE2-regulated ER stress in the skeletal muscle was also dependent on the IKK $\beta / N_{F}$ KB/IRS-1 signaling pathway as in the liver.

\section{Discussion}

This study provided a novel avenue to treat skeletal muscle disease and even other ER stress or mitochondrialassociated pathologies. We demonstrated the amount of lipid accumulation was increased in the skeletal muscle of 


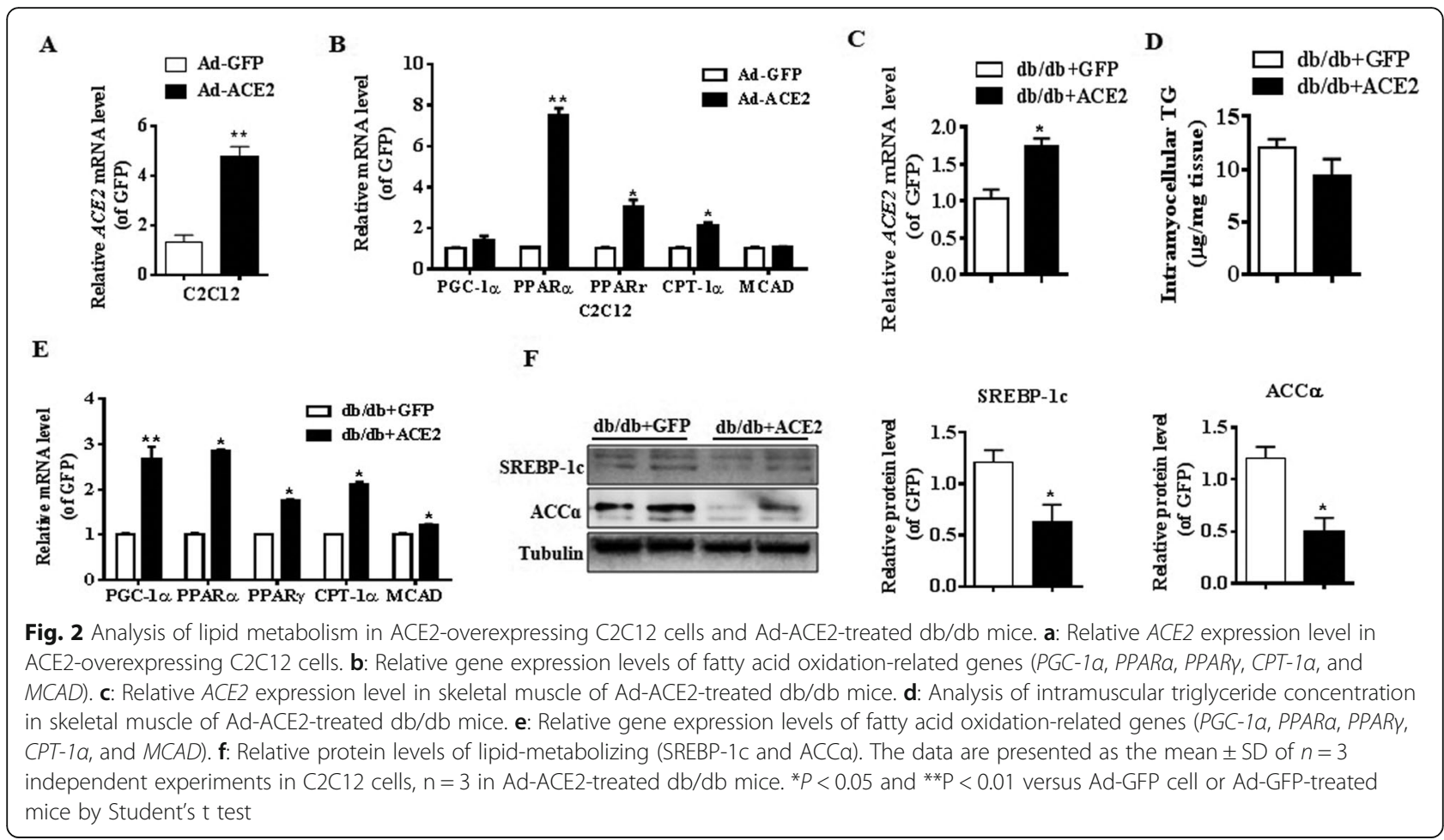

the ACE2 knockout mice, and the expression of ER stress and mitochondrial function related proteins in skeletal muscle were affected by the lack of ACE2. Moreover, ACE2 up-regulation improved skeletal muscle lipid metabolism and ER stress genes in the $\mathrm{C} 2 \mathrm{C} 12$ cells. Importantly, ACE2 may significantly ameliorate skeletal muscle lipid metabolism, ER stress and mitochondrial function in the Ad-ACE2-treated $\mathrm{db} / \mathrm{db}$ mice.

Increasing fatty acid oxidation while reducing intramuscular lipids is considered as an effective mean to improve insulin sensitivity. PGC- $1 \alpha$ has been implicated in the regulation of skeletal muscle oxidative metabolism and mitochondrial biogenesis. As a transcriptional coactivator, PGC- $1 \alpha$ activates several transcription factors to drive transcription of vast gene networks involved in many aspects of energy homeostasis, including glucose utilization and fatty acid oxidation, as well as mitochondrial biogenesis and function [15]. Some key transcriptional regulators, such as LXR $\alpha$ and SREBP-1c, coordinately control the lipogenesis, which increase the expression of key lipogenic genes, including those for FAS, SCD1 and ACC [16]. ACC1 converts acetyl-CoA to malonyl-CoA and inhibits fatty acid entry into the mitochondria reducing $\beta$-oxidation. In this study, we illustrated that skeletal muscle TG contents were significantly higher in the $A C E 2^{-/ y}$ mice than that in the WT mice. Subsequently, we also found the mRNA levels of fatty acid oxidation genes PGC-1 $\alpha, P P A R \alpha$, $P P A R \gamma, C P T-1 \alpha$ and MCAD decreased in the ACE2 KO mice, and increased in the ACE2-overexpressing $\mathrm{C} 2 \mathrm{C} 12$ cells and the $\mathrm{db} / \mathrm{db}$ mice. Meanwhile, the protein levels of lipogenesis proteins ACC $\alpha$ and SREBP-1C increased in the ACE2 KO mice, and decreased in the ACE2-overexpressing $\mathrm{db} / \mathrm{db}$ mice. Accordingly, these results suggested that ACE2 may regulate intramuscular fat accumulate in mice.

It demonstrated the alterations in mitochondria and ER physical interactions contribute to insulin resistance [17]. Indeed, mitochondria and ER interact at contact points, called mitochondria-associated endoplasmic reticulum membranes, in order to exchange calcium $\left(\mathrm{Ca}^{2+}\right)$ and lipids, thus regulating cell metabolism and fate [15]. In consequence of ER stress, an adaptive process named UPR is triggered. Three distinct branches of the UPR system can be initiated by transmembrane effector signal transduction proteins-protein kinase R (PKR)-like ER kinase (PERK), inositol requiring enzyme 1 alpha (IRE1 $\alpha$ ), and activating transcription factor 6 (ATF6). The UPR consists of three signaling branches which are initiated by signals such as the dissociation of BiP (GRP78) from the intracellular receptor domains of the ER. These signals activate combinations of the three stress sensors, protein kinase RNA-like PERK, ATF6 and inositol-requiring enzyme $1 \alpha($ IRE $1 \alpha)$. CHOP is a downstream effector of all the three branches of the UPR [18]. Enhanced CHOP expression has several effects on cells including alteration of the balance of pro- and anti-apoptotic proteins that act on mitochondria [18]. In RAS, Ang II and ACE2 have been reported to induce ER stress via GRP78/eIF2 $\alpha / A T F 4 /$ CHOP axis in the liver $[10,19]$. In the present study, the 


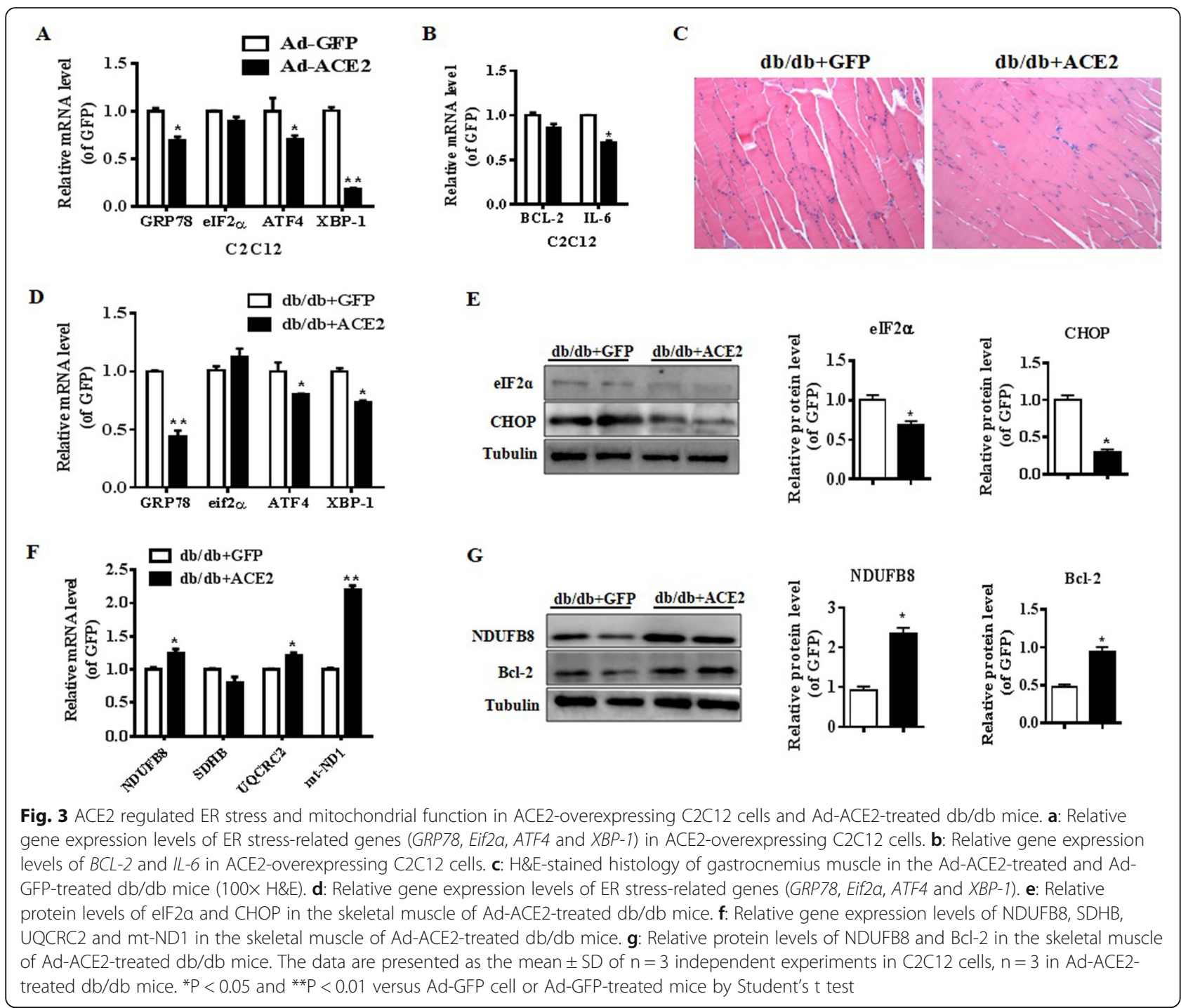

changes in GRP78/eIF2 $\alpha / \mathrm{XBP}-1 / \mathrm{ATF} 4 / \mathrm{CHOP}$ expression suggested that ACE2 ameliorates ER stress in skeletal muscle and liver may through the same pathway. The mechanism underlying this process could involve the ability of ACE2 to regulate GRP78/ eIF2 $\alpha /$ XBP-1/ATF4/ CHOP pathway.

Mitochondria regulate energy homeostasis by metabolizing nutrients, generating ATP and heat. In skeletal muscle, substantial pieces of evidence show that mitochondrial dysfunctions, in terms of number and functionality, are jointly liable for IR [20, 21]. The respiratory electron transport chain complexes I-IV which transfer the electron in the inner mitochondria membrane and the ATP-synthase enzyme (Complex V) play a critical role in mitochondrial oxidation [22]. Here, we showed that SDHB, NDUFB8 and UQCRC2 were down-regulated in the ACE2 KO mice. Consistently, NDUFB8 and UQCRC2 were down-regulated in the Ad-ACE2-treated $\mathrm{db} / \mathrm{db}$ mice. These data suggested that ACE2 can improve skeletal muscle mitochondria function by regulating respiratory electron transport chain complexes.

Activation of the pro-inflammatory transcription NF$\mathrm{\kappa B}$ has been connected to the impairment of insulin signaling induced by the ER stress in skeletal muscle [23]. The UPR is mainly mediated by the activation of IRE- $1 \alpha$, PERK/ eIF2- $\alpha$, and ATF6 signaling pathways. These three cellular pathways can interact with several inflammatory signals, including NF-kB [24]. It has been reported that UPR reduces the NF- $\kappa B$ inhibitor IкB $\alpha$ through several mechanisms $[25,26]$, which results in $\mathrm{NF}-\mathrm{KB}$ activation and the regulation of genes involved in inflammation and insulin resistance [24]. Given that accumulation of intracellular lipid species can activate cellular signaling cascades conducive to $\mathrm{NF} K \mathrm{~B}$ activation [27], we check the IKK $\beta / N F \kappa B$ signal pathway. Of interest, ACE2 down-regulation resulted in the increased 

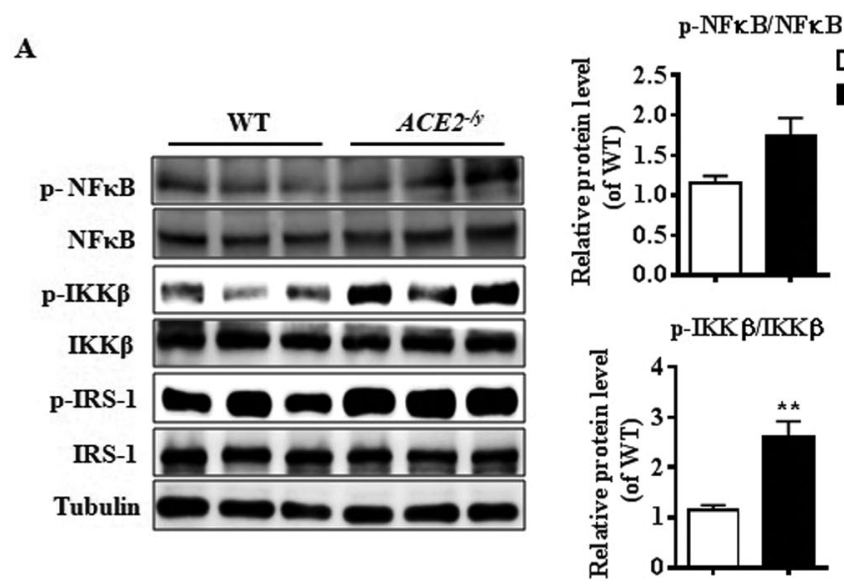

WT
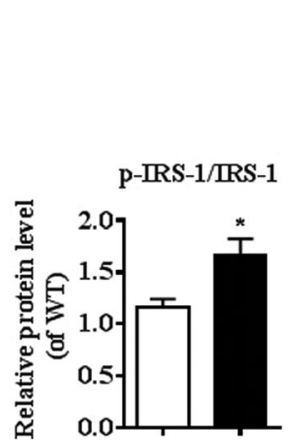

B

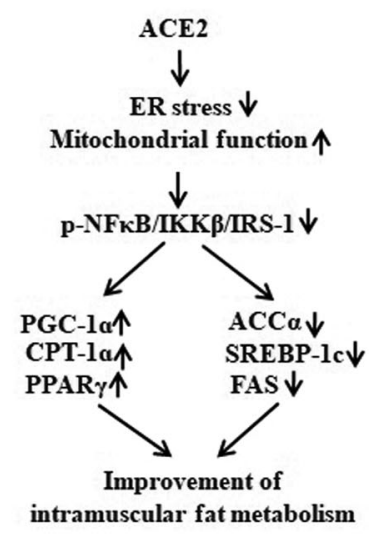

Fig. 4 Analysis of IKKB/NFKB/IRS-1 pathway in skeletal muscle of $A C E 2^{-1 y}$ mice. a: Relative protein levels of NFKB (p-NFKB), IKKB (p-IKKB), and IRS-1 (Ser307) in skeletal muscle of ACE2 ${ }^{-1 y}$ mice. b: Proposed model of intramuscular fat metabolism amelioration by the ACE2. The up- or downregulation of metabolic pathways is indicated by arrows. ( $\uparrow$ for up-regulation and $\downarrow$ for down-regulation). The data are presented as the mean \pm SD of $n=3$ in $A C E 2^{-1 y}$ mice. ${ }^{*} P<0.05$ versus WT by Student's $t$ test

expression of the phosphorylation of IKK $\beta$ and NFkB in the skeletal muscle of the ACE2 KO mice. The insulinsignaling pathway requires insulin receptor substrates (IRS-1 and IRS-2). IRS-1 has a major role in skeletal muscle [28]. Serine hyperphosphorylation of IRS-1 is a marker of IR in peripheral tissues, which leads to subsequent activation of PI3K pathway [29]. Akt is a key protein involved in PI3K pathway, its phosphorylation promotes the metabolic activities in skeletal muscle [30]. It's remarkable that ACE2 down-regulation increased expression of the phosphorylation of IRS-1 in the skeletal muscle of the ACE2 KO mice. However, one previous study showed that phosphorylated Akt in the soleus muscle equally in the standard diet-fed ACE2KO mice compared with the WT mice [31]. These findings suggest that ACE2 mediate ER stress and mitochondria function in intracellular lipid metabolism, which was involved in the regulation of the IKK $\beta / \mathrm{NF \kappa B} / \mathrm{IRS}-1$ pathway, but not Akt pathway.

\section{Conclusions}

As shown in Fig. 4b, ACE2 ameliorates intramyocellular lipid metabolism could involve the ability of regulating ER stress and mitochondria function in skeletal muscle. The underlying mechanism is mediated partly through the activation of $\mathrm{NF \kappa B} / \mathrm{IKK} \beta / \mathrm{IRS}-1$ signaling pathway. This study may further provide a strategy for treating insulin resistance in skeletal muscle.

\footnotetext{
Abbreviations

ACCa: Acetyl-CoA carboxylase a; ACE2: Angiotensin-converting enzyme 2; ACE2 ${ }^{-1 y}$ : ACE2 knockout mice; Ang-(1-7): Angiotensin-(1-7); ATF4: Activating transcription factor-4; ATF6: Activating transcription factor 6; BiP: Binding immunoglobulin protein; CHOP: C/EBP homologous protein; CPT1a: Carnitine palmitoyltransferase 1 a; DM: Differentiation medium; elF2a: eukaryotic translation initiation factor 2a; ER: Endoplasmic reticulum;
}

FAs: Fatty acids; GM: Growth medium; GRP78: Glucose regulated protein 78; GTT: Glucose tolerance tests; IRE 1a: Inositolrequiring enzyme1 a; IRE1a: Inositol requiring enzyme 1 alpha; LXRa: Liver X receptor-a; MCAD: Medium chain acy-CoA dehydrogenase; mt-ND1: mitochondrial encoded NADH dehydrogenase 1; PERK: Pancreatic endoplasmic reticulum kinase; PGC-1a: PPARY coactivator 1a; PPARa: Peroxisome proliferatoractivated receptor alpha; PPARY: Peroxisome proliferator-activated receptor gamma; RAS: Renin-angiotensin system; SDHB: Succinate dehydrogenase subunit B; SREBP-1c: Sterol regulatory element-binding protein-1 c; TG: Triglyceride; UPR: Unfolded protein response; UQCRC2: Ubiquinolcytochrome c reductase complex core protein 2; WT: Wild-type; XBP-1: Xbox-binding protein-1

\section{Acknowledgements}

We sincerely thank the Xiu Tuo, Yi-Chen Zhang for technical assistance.

\section{Authors' contributions}

Xi Cao conceived the idea for the study, designed the experiments, performed the experiments, and wrote and edited the manuscript. Xin-Meng Lu performed the experiments and edited the manuscript. Xiu Tuo, Jing-Yi Liu, Yi-Chen Zhang, and Li-Ni Song performed the experiments. Zhi-Qiang Cheng edited the manuscript. Jin-Kui Yang and Zhong Xin conceived the idea for the study, designed the experiments, and edited the manuscript. All authors read and approved the final manuscript.

\section{Funding}

This work was supported by the Foundation of Precision Medicine Research, State Key Development Program, China (2017YFC0909600); National Natural Science Foundation of China (81670774); Beijing Hospitals Authority Youth Programme (QML20170205) and Scientific Research Fund of Beijing Tongren Hospital, Capital Medical University (2014-YJJ-GGL-040).

\section{Availability of data and materials}

All data generated or analyzed during this study are included in this published article.

\section{Ethics approval}

All animals were handled in accordance with the protocol approved by the Ethics Committee of Animal Research at Beijing Tongren Hospital, Capital Medical University, Beijing, China.

Consent for publication

Not applicable 


\section{Competing interests}

The authors have no conflicts of interest to disclose.

\begin{abstract}
Author details
'Beijing Key Laboratory of Diabetes Research and Care, Beijing Diabetes institute, Department of Endocrinology, Beijing Tongren Hospital, Capital Medical University, Beijing 100730, China. ${ }^{2}$ Department of Endocrinology, Beijing Ditan Hospital, Capital Medical University, Beijing 100015, China. ${ }^{3}$ Department of Pharmacology and Molecular Sciences, Johns Hopkins University School of Medicine, Baltimore, MD 21205, USA
\end{abstract}

Received: 28 June 2019 Accepted: 5 November 2019

Published online: 27 November 2019

\section{References}

1. Glimcher LH, Lee AH. From sugar to fat: how the transcription factor XBP1 regulates hepatic lipogenesis. Ann N Y Acad Sci. 2009;1173(Suppl 1):E2-9.

2. Hotamisligil GS. Endoplasmic reticulum stress and the inflammatory basis of metabolic disease. Cell. 2010;140(6):900-17.

3. Eaton S. Control of mitochondrial beta-oxidation flux. Prog Lipid Res. 2002; 41(3):197-239

4. Tocchetti CG, Caceres V, Stanley BA, Xie C, Shi S, Watson WH, O'Rourke B, Spadari-Bratfisch RC, Cortassa S, Akar FG, Paolocci N, Aon MA. GSH or palmitate preserves mitochondrial energetic/redox balance, preventing mechanical dysfunction in metabolically challenged myocytes/hearts from type 2 diabetic mice. Diabetes. 2012;61(12):3094-105

5. Lopaschuk GD, Ussher JR, Folmes CD, Jaswal JS, Stanley WC. Myocardial fatty acid metabolism in health and disease. Physiol Rev. 2010;90(1):207-58.

6. Seghieri $M$, Trico $D$, Natali $A$. The impact of triglycerides on glucose tolerance: lipotoxicity revisited. Diabetes Metab. 2017;43(4):314-22.

7. Wei Y, Clark SE, Morris EM, Thyfault JP, Uptergrove GM, Whaley-Connell AT, Ferrario CM, Sowers JR, Ibdah JA. Angiotensin II-induced non-alcoholic fatty liver disease is mediated by oxidative stress in transgenic TG (mRen2)27(Ren2) rats. J Hepatol. 2008;49(3):417-28.

8. Cao X, Yang FY, Xin Z, Xie RR, Yang JK. The ACE2/Ang-(1-7)/mas axis can inhibit hepatic insulin resistance. Mol Cell Endocrinol. 2014;393(1-2):30-8.

9. Santos RA, Ferreira AJ, Verano-Braga T, Bader M. Angiotensin-converting enzyme 2, angiotensin-(1-7) and mas: new players of the renin-angiotensin system. J Endocrinol. 2013;216(2):R1-R17.

10. Cao X, Song LN, Zhang YC, Li Q, Shi TT, Yang FY, Yuan MX, Xin Z, Yang JK. Angiotensin-converting enzyme 2 inhibits endoplasmic reticulum stressassociated pathway to preserve nonalcoholic fatty liver disease. Diabetes Metab Res Rev. 2019;35(4):e3123.

11. Shi TT, Yang FY, Liu C, Cao X, Lu J, Zhang XL, Yuan MX, Chen C, Yang JK. Angiotensin-converting enzyme 2 regulates mitochondrial function in pancreatic beta-cells. Biochem Biophys Res Commun. 2018;495(1):860-6.

12. Sukumaran V, Veeraveedu PT, Gurusamy N, Lakshmanan AP, Yamaguchi K, Ma M, Suzuki K, Nagata M, Takagi R, Kodama M, Watanabe K. Olmesartan attenuates the development of heart failure after experimental autoimmune myocarditis in rats through the modulation of ANG 1-7 mas receptor. Mol Cell Endocrinol. 2012;351(2):208-19.

13. Nguyen $\mathrm{H}$, Uhal BD. The unfolded protein response controls ER stressinduced apoptosis of lung epithelial cells through angiotensin generation. Am J Physiol Lung Cell Mol Physiol. 2016;311(5):L846-54.

14. Echeverria-Rodriguez O, Del Valle-Mondragon L, Hong E. Angiotensin 1-7 improves insulin sensitivity by increasing skeletal muscle glucose uptake in vivo. Peptides. 2014;51:26-30.

15. Lin J, Handschin C, Spiegelman BM. Metabolic control through the PGC-1 family of transcription coactivators. Cell Metab. 2005;1(6):361-70.

16. Schultz JR, Tu H, Luk A, Repa JJ, Medina JC, Li L, Schwendner S, Wang S, Thoolen M, Mangelsdorf DJ, Lustig KD, Shan B. Role of LXRs in control of lipogenesis. Genes Dev. 2000;14(22):2831-8.

17. Tubbs E, Rieusset J. Metabolic signaling functions of ER-mitochondria contact sites: role in metabolic diseases. J Mol Endocrinol. 2017;58(2): R87-R106

18. Oyadomari S, Mori M. Roles of CHOP/GADD153 in endoplasmic reticulum stress. Cell Death Differ. 2004:11(4):381-9.

19. Ha TS, Park HY, Seong SB, Ahn HY. Angiotensin II induces endoplasmic reticulum stress in podocyte, which would be further augmented by Pl3kinase inhibition. Clin Hypertens. 2015;21:13.
20. Petersen KF, Dufour S, Befroy D, Garcia R, Shulman GI. Impaired mitochondrial activity in the insulin-resistant offspring of patients with type 2 diabetes. N Engl J Med. 2004;350(7):664-71.

21. Lowell BB, Shulman GI. Mitochondrial dysfunction and type 2 diabetes. Science. 2005;307(5708):384-7.

22. Lemarie A, Grimm S. Mitochondrial respiratory chain complexes: apoptosis sensors mutated in cancer? Oncogene. 2011;30(38):3985-4003.

23. Kim JK, Kim YJ, Fillmore JJ, Chen Y, Moore I, Lee J, Yuan M, Li ZW, Karin M, Perret $P$, Shoelson SE, Shulman Gl. Prevention of fat-induced insulin resistance by salicylate. J Clin Invest. 2001;108(3):437-46.

24. Garg AD, Kaczmarek A, Krysko O, Vandenabeele P, Krysko DV, Agostinis P. ER stress-induced inflammation: does it aid or impede disease progression? Trends Mol Med. 2012;18(10):589-98.

25. Hu P, Han Z, Couvillon AD, Kaufman RJ, Exton JH. Autocrine tumor necrosis factor alpha links endoplasmic reticulum stress to the membrane death receptor pathway through IRE1alpha-mediated NF-kappaB activation and down-regulation of TRAF2 expression. Mol Cell Biol. 2006;26(8):3071-84

26. Yamazaki H, Hiramatsu N, Hayakawa K, Tagawa Y, Okamura M, Ogata R, Huang T, Nakajima S, Yao J, Paton AW, Paton JC, Kitamura M. Activation of the Akt-NF-kappaB pathway by subtilase cytotoxin through the ATF6 branch of the unfolded protein response. J Immunol. 2009;183(2):1480-7.

27. Wellen KE, Hotamisligil GS. Inflammation, stress, and diabetes. J Clin Invest. 2005;115(5):1111-9.

28. Honma M, Sawada S, Ueno Y, Murakami K, Yamada T, Gao J, Kodama S, Izumi T, Takahashi K, Tsukita S, Uno K, Imai J, et al. Selective insulin resistance with differential expressions of IRS-1 and IRS-2 in human NAFLD livers. Int J Obes. 2018;42(9):1544-55.

29. Boller S, Joblin BA, Xu L, Item F, Trub T, Boschetti N, Spinas GA, Niessen M. From signal transduction to signal interpretation: an alternative model for the molecular function of insulin receptor substrates. Arch Physiol Biochem. 2012;118(3):148-55.

30. Kubota H, Noguchi R, Toyoshima Y, Ozaki Y, Uda S, Watanabe K, Ogawa W, Kuroda S. Temporal coding of insulin action through multiplexing of the AKT pathway. Mol Cell. 2012;46(6):820-32.

31. Takeda M, Yamamoto K, Takemura Y, Takeshita H, Hongyo K, Kawai T, Hanasaki-Yamamoto H, Oguro R, Takami Y, Tatara Y, Takeya Y, Sugimoto K, et al. Loss of ACE2 exaggerates high-calorie diet-induced insulin resistance by reduction of GLUT4 in mice. Diabetes. 2013;62(1):223-33.

\section{Publisher's Note}

Springer Nature remains neutral with regard to jurisdictional claims in published maps and institutional affiliations.

Ready to submit your research? Choose BMC and benefit from:

- fast, convenient online submission

- thorough peer review by experienced researchers in your field

- rapid publication on acceptance

- support for research data, including large and complex data types

- gold Open Access which fosters wider collaboration and increased citations

- maximum visibility for your research: over $100 \mathrm{M}$ website views per year

At BMC, research is always in progress.

Learn more biomedcentral.com/submissions 